\title{
PELATIHAN PENDIDIKAN KARAKTER BAGI MAHASISWA BARU STIE DHARMA BHARATA KENDARI DALAM MEMBANGUN JIWA MERDEKA MELALUI NILAI-NILAI PANCASILA
}

\author{
Zulfikar Putra ${ }^{1}$ \\ Farid Wajdi ${ }^{*}$ \\ 1,2 Universitas Sembilanbelas November, Kolaka, Indonesia \\ zulfikarputra2016@gmail.com ${ }^{1)}$ \\ wajdikf83@usn.ac.id $^{2 *}$
}

Kata Kunci: [Karakter, Jiwa

Merdeka, Nilai-Nilai

Pancasila]

Published by:

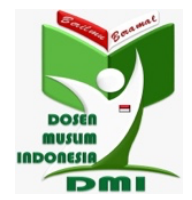

Abstrak: Tujuan penelitian ini adalah untuk menumbuhkan nilai-nilai karakter mahasiswa baru dalam konsep jiwa merdeka melalui nilai-nilai Pancasila. Penelitian ini menggunakan focus drup discussion. Teknik analisis data dilakukan degan cara mengkategorikan dan mengklasifikasikan berdasarkan analisi secara logis, kemudian ditafsirkan dalam konteks keseluruhan maslah penelitan, Temuan hasil penelitian, bahwa mahasiswa baru pelatihan pendidikan karakter belum memiliki kemerdekaan jiwa, hal tersebut dapat dilihat dari keputusan menempuh pendidikan di jenjang Perguruan Tinggi dipengaruhi oleh orang lain bukan atas kehendak sendiri. Penelitian ini diharapkan mahasiswa mampu mengimplementasikan konsep jiwa merdeka melalui nilai-nilai Pancasila.

Copyright (C) 2021 The Author(s)

This article is licensed under CC BY 4.0 License (cc) $\mathrm{BY}$

https://dmi-journals.org/jai 


\section{Pendahuluan}

Pembentukan karakter bagi para peserta didik merupakan sebuah keniscayaan bagi para pendidik dalam mengembangkan kepribadian yang ada dalam diri mereka sebagai bekal menghadapi kehidupan yang multikultural. Proses pembentukan karakter tersebut tentunya dilakukan dalam tripusat pendidikan, yaitu lingkungan keluarga (informal), lingkungan masyarakat (non-formal), dan juga lingkungan pemerintah (formal/satuan pendidikan). Sehingga, pemerintah sebagai pemegang kendali sistem ketatanegaraan memperkuatnya melalui undang-undang yang telah ditetapkan.

Undang-Undang No.12 Tahun 2012 Pasal 4 telah mengatur, bahwa Pendidikan Tinggi memiliki 3 (tiga) fungsi yaitu (1) mengembangkan kemampuan dan membentuk watak serta peradaban bangsa yang bermartabat dalam rangka mencerdaskan kehidupan bangsa; (2) mengembangkan sivitas akademika yang inovatif, responsive, kreatif, terampil, berdaya saing dan kooperatif melalui pelaksanaan Tri Dharma; (3) mengembangkan ilmu pengetahuan dan teknologi dengan memperhatikan dan menerapkan nilai Humaniora (Undang-Undang Tentang Pendidikan Tinggi, 2012). Peran strategis kampus dalam membentuk karakter mahasiswa, menjadi bagian tanggung jawab moril sebagaimana yang diamanatkan dalam undang-undang. Perguruan Tinggi yang memiliki fungsi pengembang ilmu pengetahuan sebagaimana yang diamantkan dalam Tridharma Perguruan Tinggi. Dosen tidak hanya bertugas mengajar tetapi juga meneliti serta melakukan pengabdian masyarakat. Olehnya, pendidikan tinggi memiliki kewajiban mentransformasi, mengembangkan serta menyebarluaskan kepada masyarakat (peserta didik) maupun masyarakat pada umumnya. Dalam hal ini adalah peran dosen yang utama yakni upayanya menjadikan lingkungan kampus memiliki karakter yang sesuai dengan budaya bangsa Indonesia (Alinurdin, 2021).

Pendidikan sebagai sarana manajemen dalam pembentukan perkembangan pribadi manusia berperan penting dalam menghadapi situasi dan kondisi kehidupan (Wajdi, 2021). Pembentukan karakter (character building) merupakan sebuah proses penanaman berupa nilai-nilai baik sebagai cerminan perilaku seseorang. Dalam perspektif pendidikan, character building merupakan proses pembinaan dalam memperbaiki atau membentuk tabiat-watak-sifat kejiwaan manusia (masyarakat) berdasarkan nilai-nilai yang terkandung dalam pancasila. Perubahan dalam character building yang positif memantapkan nilai-nilai Pancasila sebagai falsafah hidup bangsa dalam mengembangkan kehidupan nasional yang lebih berkualitas (Putra, Zulfikar; Wajdi, 2021). Pada dasarnya tujuan pendidikan karakter adalah untuk mendorong lahirnya manusia yang baik, yang memiliki kepribadian menarik, beretika, bersahaja, jujur cerdas, peduli dan tangguh. Istilah karakter dapat diartikan sebagai sistem daya juang (daya dorong, daya gerak dan gaya hidup) yang berisikan tata nilai kebajikan dan moral yang terpatrit dalam diri manusia (Putra, 2018). Pendidikan karakter adalah sebagai cara berpikir dan berperilaku yang menjadi ciri khas setiap individu untuk hidup dan bekerjasama, baik dalam lingkungan keluarga, masyarakat, bangsa dan negara (Wajdi, 2020).

Mewujudkan manusia Indonesia yang unggul, maka setidaknya penguasaan ilmu pengetahuan dan teknologi (Iptek) serta iman dan taqwa (Imtaq) menjadi sesuatu yang mesti dimiliki. Setelah bangsa Indonesia menyatakaan merdeka dari belenggu penjajahan, maka pekerjaan berikutnya adalah bagaimana bangsa ini mampu membangun dan memanajemeni sumber daya manusia (SDM) menjadi manusia yang 
merdeka. Merdeka dalam artian bahwa jiwa yang tidak terbelenggu dengan kepentingan individu dan kelompok/golongan yang sifatnya temporal. Membangun jiwa merdeka adalah mengubah cara pandang, pikiran, sikap dan perilaku agar berorientasi pada kemajuan. Membangun jiwa merdeka melalui nilai-nilai Pancasila, dimana para mahasiswa akan diberikan pemahaman tentang jiwa merdeka dalam erti membangun jati diri agar terlepas dari terbelenggunya sifat duniawi yang tidak menjadikan kita merdeka kemudian selangkah demi selangkah kita mengikuti jati diri untuk menemukan Tuhan Yang Maha Esa. Membangun jiwa merdeka, diperlukan kecerdasan holistik, yaitu suatu filsafat pendidikan yang bersumber dari pemikiran bahwa pada dasarnya setiap individu dapat menemukan identitas dirinya, tujuan hidupnya dan makna hidupnya. Melalui hubungan dengan yang dijalin dengan masyarakat dan nilai-nilai spiritual yang dimilikinya serta lingkungan alam sekitarnya. Dengan demikian pengembangan kecerdasan holistik ini haruslah berbasis pada filsafat Pancasila, karena identitas bangsa sangat penting bagi suatu bangsa dalam membangun karakter dan sikap bangsanya, terutama di era negara kebangsaan (National State) sekarang ini. Karena bangsa yang kehilangan identitasnya akan menjadi bangsa yang terombang ambing, yang pada akhirnya akan menjadi bangsa yang hancur, karena tidak memiliki karakter dan tidak pernah bis amengambil sikap. Bangsa Indonesia telah sepakat Pancasila dijadikan sebagai identitas atau jati diri bangsa dimana bangsa Indonesia dikenal sebagai bangsa yang percaya dan sangat menjunjung tinggi bahwa kebenaran yang berasal dari wahyu Tuhan merupakan sumber kebenaran yang utama (pola pikir Magis Danken). Indonesia sebagai negara berkembang senantiasa berupaya menghadapi dan bersaing terhadap tantangan-tantangan guna menuju negara Indonesia yang maju. Hal tersebut diperkuat dengan adanya nilai-nilai moral yang terdapat pada budaya, agama, dan nilai karakter bangsa, yaitu nilai-nilai pancasila sebagai ideologi dan jati diri (falsafah) bangsa (Wajdi, Farid; Putra, 2021).

Mahasiswa merupakan generasi pewaris keberlanjutan kepemimpinan bangsa kedepan. Oleh karena itu diperlukan cita-cita besar, kerja-kerja besar serta mental yang tangguh dalam mewujudkan bangsa berdaulat, berkemajuan dan berkarakter. Dengan demikian, pelatihan karakter bagi mahasiswa dalam membangun jiwa merdeka dapat menjadi wadah bagi mahasiswa untuk meningkatkan confident (kepercayaan diri) sebagai seorang warga bangsa.

\section{Metode Pelaksanaan}

Tujuan pelatihan ini adalah untuk menumbuhkan nilai-nilai mahasiswa baru dalam konsep jiwa merdeka melalui nilai-nilai Pancasila.

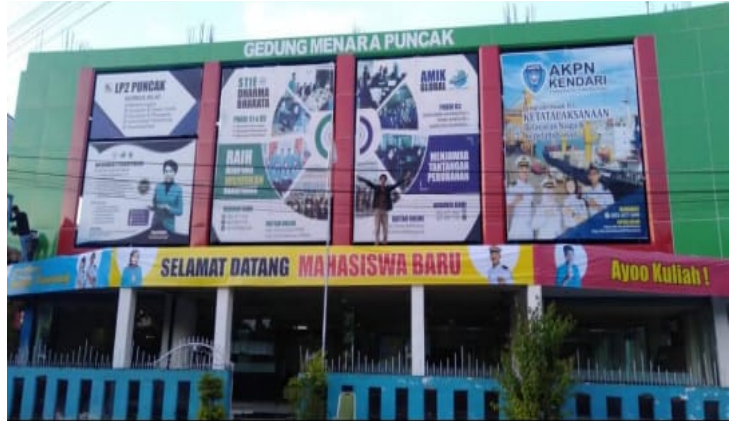

Gambar 1. Gedung STIE DB Kendari

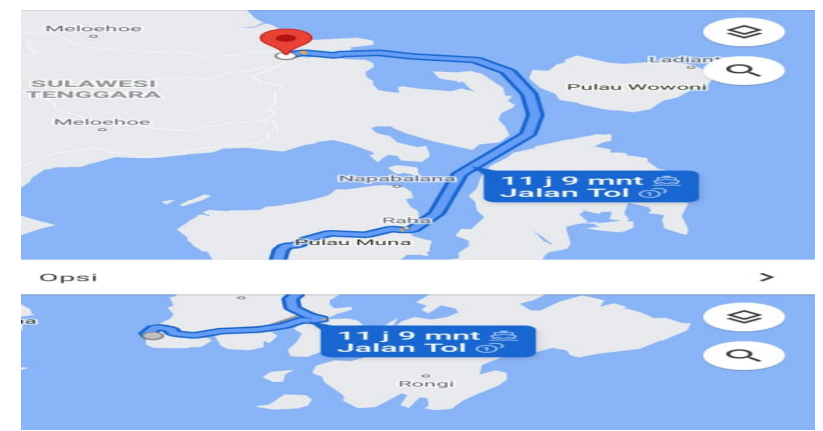

Gambar 2. Peta Lokasi STIE Dharma Bharata 
Adapun target yang ingin dihasilkan dari kegiatan pengabdian ini adalah untuk meningkatkan pemahaman mahasiswa baru mengenai pendidikan karakter. Oleh karena itu, diusulkan kerangka pemecahan masalah secara operasional sebagai berikut:

1. Penyelenggaraan pelatihan pendidikan karakter secara rutin (setiap penerimaan mahasiswa baru)

2. Pendidikan Karakter, terintegrasi dengan mata kuliah Kepribadian yang ada di STIE Dharma Bharata Kendari

3. Diharapkan dalam kegiatan ini, dapat merubah mindset mahasiswa tentang jiwa merdeka dalam bingkai nilai-nilai pancasila dalam teraktualisasi dalam kehidupan kampus, masyarakat, bangsa dan negara

Metode pelatihan yang digunakan untuk mendukung keberhasilan program adalah Focus Group Discussion (FGD) yaitu sebagai suatu metode untuk memperoleh produk data/informasi melalui interaksi sosial sekelompok individu yang dalam interaksi tersebut. Sesama individu saling mempengaruhi satu dengan yang lainnya (Hollander, 2004). Adapun pelatihan ini membahas mengenai kemerdekaan berpikir, kemerdekaan bersikap dan kemerdekaan bertingkah laku dalam bingkai nilai-nilai Pancasila.

Keberhasilan kegiatan ini dapat diketahui dengan melihat keterlibatan dan antusias peserta. Keterlibatan peserta dapat dilihat dari absen peserta kegiatan dan antusiasme peserta dilihat dari motivasi peserta selama kegiatan berlangsung. Digunakan juga metode angket/kuesioneruntuk mengumpulkan data mengenai respons mahasiswa terhadap pelaksanaan kegiatan. Setelah kegiatan pelatihan, dilaksanakan monitoring dan evaluasi oleh panitia pelaksana untuk melihat dan mengetahui perubahan cara berfikir, sikap dan tingkah laku mahasiswa baru STIE Dharma Bharata Kendari.

\section{Hasil dan Pembahasan}

Kegiatan pengabdian ini dilakukan pada mahasiswa baru Sekolah Tinggi Ilmu Ekonomi (STIE) Dharama Bharata Kendari Provinsi Sulawesi Tenggara. Pengabdian ini dilaksanakan selama 2 (dua) hari yaitu pada hari Jum'at s/d Sabtu tanggal 9-10 Oktober 2020. Peserta dalam kegiatan pelatihan ini berjumlah 30 orang. Kegiatan ini erat kaitannya dengan pengembangan softskill mahasiswa baru, dalam memasuki dunia yang baru. Lingkungan yang berbeda dengan lingkungan sekolah yang selama ini mereka berinteraksi. Mengembangkan jiwa merdeka, hakikatnya belajar dari teks proklamasi 17 Agustus 1945, maka dapat ditemukan kalimat "... bahwa sesungguhnya kemerdekaan itu adalah hak segala bangsa...." sementara itu bila melihat pembukaan UUD 1945 disana ditemukan cita-cita proklamasi adalah menjadi bangsa yang merdeka, bersatu, berdaulat, adil dan makmur. Sementara dalam konteks kekinian Mendikbud dan Ristek juga telah mencanangkan program Merdeka Belajar dan Kampus Merdeka (MBKM). Dengan demikian pelatihan ini juga sejalan dengan lagu kebangsaan Indoneia Raya yang mengatakan ".... bangunlah jiwanya, bangunlah raganya". Inilah arti penting dari pelatihan membangun jiwa merdeka".

Kegiatan Pelatihan Pendidikan Karakter Bagi Mahasiswa Baru STIE Dharma Bharata Kendari dalam Membangun Jiwa Merdeka Melalui Nilai-Nilai Pancasila, merupakan salah satu program rutin dari Perjanjian Kerjasama yang dilakukan oleh Program Studi Pendidikan Pancasila dan Kewarganegaraan, Fakultas Keguruan dan Ilmu 
Pendidikan, Universitas Sembilanbelas November Kolaka dengan Sekolah Tinggi Ilmu Ekonomi Dharma Bharata Kendari. Dalam kegiatan tersebut, ada 3 (tiga) narasumber yang terdiri dari 1 (satu) orang dari dosen STIE Dharma Bharata yaitu Ibu Dwi Kartika Pranangingrum, SE., ME.Ak dengan materi yang berjudul "Penguatan dan Strategi Pengembangan Karakter" dan 2 (dua) orang dosen dari Universitas Sembilanbelas November Kolaka yaitu Bapak Zulfikar Putra, SH., M.Pd dengan materi berjudul "Membangun Jiwa Merdeka berdasarkan Nilai-Nilai Pancasila dan Bapak Dr. H. Farid Wajdi, S.Pd.I., M.Si dengan materi berjudul "Peran Filsafat Pendidikan Dalam Penguatan Pendidikan Karakter".

Pembangunan Sumber Daya Manusia (SDM), masih menjadi perhatian serius pemerintah khususnya tentang pembangunan nilai-nilai karakter (character building). Maka, peran lembaga pendidikan tidak hanya bertugas memindahkan ilmu pengetahuan dan teknologi kepada generasi muda, tetapi juga internalisasi nilai-nilai luhur dan ideal bagi kehidupan antar generasi (Putra, 2018). Dalam hal ini, pendidikan karakter dalam membentuk kepribadian mahasiswa sangat penting adanya. Dengan adanya pendidikan karakter, mahasiswa dapat mempelajari dan memahami bagaimana menggunakan kebebasan berpendapat nereka dan merefleksikan karakter yang baik dalam setiap sikap dan aktivitasnya. Untuk meningkatkan SDM khususnya pada pendidikan karakter, nilai-nilai Pancasila hendaknya diresapi dan diimplementasikan secara nyata. Setiap sila yang terkandung dalam Pancasila merupakan modal dasar pendidikan karakter (Abidin, 2012). Nilai-nilai yang dapat diambil dari Pancasila untuk menguatkan pendidikan karakter adalah:

a. Pancasila pada sila ke-1, ada nilai toleransi beragama dalam pendidikan karakter mahasiswa;

b. Pancasila pada sila ke-2, yaitu nilai memahami dan menghargai sesame manusia sehingga membentuk karakter yang beradab;

c. Pancasila pada sila ke-3, dapat memahami nilai persatuan dan cinta tanah air sehingga pendidikan selalu mengutamakan keragaman budaya di Indonesia;

d. Pancasila pada sila ke-4, menjadi nilai penting untuk memahami kehidupan demokrasi yang sesuai dengan hati nurani serta adanya keharusan taat pada hukum sehingga menjadi pribadi yang disiplin;

e. Pancasila pada sila ke-5, mengandung nilai memperjuangkan kepentingan bersama dalam kehidupan bersosialisasi sehingga keadilan social selalu ada dalam kehidupan sehari-hari.

\section{Kesimpulan}

Pelatihan pendidikan karakter menjadi wadah bagi mahasiswa baru untuk memberi pembekalan serta konsep awal mengenai jiwa merdeka melalui nilai-nilai Pancasila. Kegiatan Pelatihan ini, banyak pelajaran yang dapat diambil. Setidaknya dari ke lima nilai Pancasila yang mencakup nilai ketuhanan, nilai kemanusiaan, nilai persatuan, nilai kerakyatan dan nilai keadilan. Dalam hal ini Pancasila harus menjadi pedoman utama dalam kehidupan bermasyarakat, berbangsa dan bernegara. Melalui kegiatan pelatihan ini, menjadi bagian dari komitmen lembaga pendidikan (kampus) untuk melahirkan insan-insan yang berkarakter dalam mengimplemtasikan dalam setiap sendi kehidupan. 


\section{Ucapan Terimakasih}

Terimakasih kami ucapkan kepada Ketua STIE Dharma Bharata Kendari dalam hal ini pribadi Ibu Dwi Kartika Prananingrum, SE., ME. Ak yang telah memfasilitasi kami dalam kegiatan pengabdian Pelatihan Pendidikan Karakter Mahasiswa Baru STIE Dharma Bharata Kendari yang kemudian dijadikan agenda rutin setiap penerimaan mahasiswa baru di STIE Dharma Bharata Kendari. Dan ucapan apresiasi yang setinggitimgginya atas kepercayaan yang diberikan kepada kami, yang diamanahi sebagai narasumber tetap dalam kegiatan pelatihan Pendidikan Karakter Mahasiswa Baru STIE Dharma Bharata Kendari. Tidak lupa, kami ucapkan terimakasih kepada Dekan FKIP USN Kolaka yang telah mempercayakan kepada kami, untuk mewakili FKIP USN Kolaka sebagai narasumber dalam kegiatan dimaksud. Semoga bantuan baik maril maupun materiil, Allah SWT membalas dengan balasan yang setimpal. Aamiin

\section{Referensi}

Abidin, Y. (2012). Model Penilaian Otentik Dalam Pembelajaran Membaca Pemahaman Berorientasi Pendidikan Karakter. Jurnal Pendidikan Karakter. https://doi.org/10.21831/jpk.v0i2.1301

Alinurdin. (2021). Urgensi dan implementasi pendidikan karakter di perguruan tinggi. Generasi Pancasila, 1(1), 1-12. http://www.openjournal.unpam.ac.id/index.php/gnp/article/view/11251

Hollander, J. A. (2004). The social contexts of focus groups. In Journal of Contemporary Ethnography. https://doi.org/10.1177/0891241604266988

Putra, Zulfikar; Wajdi, F. (2021). Implementation of Leadership Values in Pancasila Paradigm as Character Building Values. Social, Humanities, and Educational Studies (SHEs): $\quad$ Conference Series, 4(4), 45-52. https://doi.org/https://doi.org/10.20961/shes.v4i4.50584

Putra, Z. (2018). Implementasi Pendidikan Pancasila sebagai Character Building Mahasiswa di Universitas Sembilanbelas November Kolaka. Jurnal Citizenship: Media Publikasi Pendidikan Pancasila Dan Kewarganegaraan, 1(1), 9-13.

Undang-Undang Tentang Pendidikan Tinggi. (2012). Undang-Undang Nomor 12 Tahun 2012. In Hukum Online.

Wajdi, Farid; Putra, Z. (2021). The Implementation of Elementary Student Character Values Among the Bajo Tribe through Pancasila Values as Character Building. Social, Humanities, and Educational Studies (SHEs): Conference Series, 4(4), 95-104. https://doi.org/https://doi.org/10.20961/shes.v4i4.50591

Wajdi, F. (2020). Nilai-Nilai Karakter Etnis Bajo Relevan Dengan Nilai Karakter Bangsa. Makassar: Yayasan Barcode.

Wajdi, F. (2021). Manajemen Perkembangan Siswa SD Melalui Peran Guru Dan Orang Tua Pada Masa Pandemi. JAMP: Jurnal Adminitrasi Dan Manajemen Pendidikan, 4(1), 41-50. http://journal2.um.ac.id/index.php/jamp/article/view/17229 